\title{
Wayang Palembang Dalam Lakon Bambang Dharmojati oleh Dalang Kiagus Wirawan Bersama Sanggar Sri Palembang
}

jurnal tari, teater, dan wayang volume 2 number 1, May 2019 page $42-51$

\author{
Aminatul Fadilla ${ }^{1}$ \\ Jurusan Teater, Fakultas Seni Pertunjukan, Institut Seni Indonesia \\ Yogyakarta
}

\begin{abstract}
This study aimed to analyzing the dynamics of the existence of the Wayang Palembang from the beginning of birth until that brought by Kiagus Wirawan with Sanggar Sri Palembang nowaday (2019). So, to be more focused, Bambang Dharmojati's sample was chosen in order to give an overview of the Wayang Palembang performance. This research was conducted using qualitative methods and ethnographic approaches. During the process of research found that Wayang Palembang is a typical art that originated from Wayang Purwa. This art began to live and be known in the community since the collapse of the Palembang Darussalam sultanate. There were three very strong cultural elements in the Wayang Palembang, namely the Melayu Palembang, Java and Cirebon. Wayang Palembang today was experiencing a decline in audience interested. This phenomenon raises fundamental questions about how the Wayang Palembang performance, how Sanggar Sri Palembang survives and why it has decreased audience interested. For this reason, Hausers, Tomars and Wolff's theories were used which said that social change in a place will present a unique art renewal in accordance with the social patterns of the community at that time, then Kernodle's structured and textured theory was used to analyzing the form of performances to be able to presenting interpretations of interested preferences show. Furthermore, the way to survive is analyzed by Scott's theory which said that efforts to fight and survive consist of open and hidden form resistance. The results of this study indicated that the Wayang Palembang performance today was still very classical in nature, resulting in a difference between public demand and the availability of performance space. However, to maintain its existence, Kiagus Wirawan and Sanggar Sri Palembang will always hold Wayang Palembang performances independently and do not care about the number of spectators.
\end{abstract}

Keywords: Wayang Palembang; performance, society, Sanggar Sri Palembang; Bambang Dharmojati

\section{Pendahuluan}

Wayang Palembang merupakan warisan budaya masyarakat Palembang yang kini sedang berada pada ambang kepunahan. Kesenian tersebut mengalami penurunan peminat yang cukup signifikan di antara meningkatnya angka pertumbuhan dalam generasi Palem- bang saat ini. Bahkan pada titik tumpu tahun 2019, dalang dan sanggar yang tersisa di seluruh Sumatera Selatan hanya tersisa satu orang dalang dan satu buah sanggar, yaitu dalang Kiagus Wirawan dengan sanggarnya yang bernama sanggar Sri Palembang.

Berdasarkan wawancara dengan Kiagus Wirawan di Kelurahan 36 Ilir, Kecamatan Ilir

\footnotetext{
1 Alamat korespondensi: Batumarta VI Madang Suku III Ogan Komering Ulu Timur Sumatera Selatan. E-mail: aminatulfadila@gmail.com; HP: 085856602572
} 
Barat 2, Desa Tangga Buntung, Kota Madya Palembang pada 21 Agustus 2018 disebutkan bahwa Wayang Palembang muncul sejak masa transisi kerajaan Sriwijaya menuju era kesultanan Palembang Darussalam sekitar abad Ke-17M dan mengalami kejayaan sekitar abad ke-20M hingga akhirnya berangsur melemah hingga tahun 2019. Pada masa 17M-19M berdasarkan data kesejarahan, Wayang Palembang mengalami perkembangan. Mulai dari dalang yang bejumlah satu orang (dalang Jawa yang diutus ke Palembang), sanggar yang belum ada, praktisi yang berjumlah sepuluh orang (pengrawit Jawa) dan konsumen yang cukup tinggi di kalangan Kesultanan Palembang Darussalam. Pada abad ke-17M hingga ke-18M terjadi migrasi besar-besaran masyarakat Jawa menuju tanah Palembang, sehingga membentuk komunitas yang cukup besar. Komunitas masyarakat Jawa selanjutnya mengirim dalang Jawa beserta pengrawit dan gamelan Jawa untuk menjadi hiburan bagi masyarakat transmigran. Tidak hanya masyarakat Jawa transmigran yang tertarik oleh pertunjukan wayang, masyarakat Palembang juga tertarik dan antusias terhadap pertunjukan wayang. Oleh sebab faktor permintaan Kesultanan Palembang Darussalam akhirnya lahirlah sepuluh dalang Wayang Palembang pertama yang merombak bahasa, tokoh-tokoh, cerita dan musik pengiring wayang Jawa menjadi gaya Palembang, sehingga pada masa Kesultanan Palembang Darussalam, Wayang Palembang sudah mulai menemukan bentuknya dengan peminat yang tinggi.

Tahun 1950 bertepatan dengan tahun berdirinya sanggar Sri Palembang seolah menjadi penutup kejayaan Wayang Palembang. Kejadian ini didasari atas teknologi modern yang sudah mulai berkembang sehingga pola perilaku masyarakat Palembang juga ikut berubah. Pada tahun 1950-2000 dalang, praktisi dan konsumen mulai menurun seiring perputaran waktu.

Memasuki tahun sembilan puluhan terjadi kemerosotan yang parah pada Wayang Palembang. Di tahun 2000 dalang-dalang dan praktisi-praktisi yang menjadi bintang pada tahun 1900-1950 satu persatu mulai meninggal dunia. Kini generasi Wayang Palembang pada tahun 2000 hanya menyisakan satu orang dalang muda yaitu Kiagus Wirawan yang memulai karir mendalang dan meneruskan warisan sanggar Sri Palembang semenjak tahun 2003 hingga saat ini. Pada saat ini (tahun 2019) Sanggar Sri Palembang merupakan satu-satunya sanggar dan kelompok praktisi Wayang Palembang yang menjadi penggerak keberlangsungan hidup Wayang Palembang. Menyadari posisi krisis ini dalang Kiagus Wirawan beserta anggota kelompok sanggar Sri Palembang memiliki sistem pemberdayaan dan cara yang unik untuk mempertahankan keberadaan Wayang Palembang.

Masyarakat Palembang hari ini menunjukkan pergerakan yang semakin menjauh dari minat menonton dan mempelajari Wayang Palembang. Gesekan dari kondisi sosial masyarakat dalam Wayang Palembang semakin hari akan semakin kuat, ini menunjukan adanya kontradiksi antara bentuk Wayang Palembang hari ini dengan dinamika masyarakat Palembang. Kondisi tersebut di atas mendorong penulis mencari lebih dalam tentang korelasi bentuk pertunjukan dan kondisi sosial masyarakat. Di antara beragam bentuk lakon Wayang Palembang, penulis memilih lakon Bambang Dharmojati. Pemilihan ini didasari alasan bahwa lakon Bambang Dharmojati merupakan lakon yang diadaptasi berdasarkan folklore Palembang dan paling sering dipentaskan. Berdasarkan penjabaran fenomena yang terjadi dalam Wayang Palembang yang digerakkan oleh sanggar Sri Palembang di atas, penulis merumuskan pertanyaan konsep yang diajukan di bawah ini, untuk mencari jawaban atas menurunnya minat masyarakat dalam menyaksikan pertunjukan Wayang Palembang hari ini.

Tidak banyak diketahui kiprah Wayang Palembang ini di bumi Sriwijaya. Hal ini disebabkan oleh hilangnya pakar atau ahli yang mengetahui seluk-beluk sejarah kesenian ini. Sumber-sumber yang tersisa mengenai sejarah Wayang Palembang hanyalah berupa rekaman audio amatir tentang pertunjukan 
Wayang Palembang yang dipagelarkan oleh beberapa dalang terdahulu. Selain itu untuk mengamati dan menganalisis keberadaan Wayang Palembang hari ini pun menjadi hal yang cukup rumit, karena dalang (narasumber primer) tersisa hanya Kiagus Wirawan dan dia memiliki traumatik tersendiri terhadap peneliti-peneliti yang datang untuk mencari data. Namun dengan pendekatan yang cukup baik, penulis berhasil mendapatkan akses untuk menelusuri latar belakang permasalahan yang terjadi di lapangan.

\section{Asal Usul Wayang Palembang}

Menurut data turun temurun yang diceritakan oleh leluhur, dalang Kiagus Wirawan dikatakan bahwa Wayang Palembang masuk ke tanah Sriwijaya pada saat runtuhnya kerajaan Sriwijaya. Kosongnya kekuasaan menyebabkan Majapahit mengekspansi wilayah ini diperkirakan sekitar tahun 1370 . Namun berdasarkan penelusuran penulis, terdapat tiga periode kerajaan yang berbeda dalam perjalanan Wayang Palembang. Penulis membagi lahirnya Wayang Palembang menjadi tiga pengaruh bagian, yaitu 1) awal kedatangan Wayang Purwa di tanah Palembang, 2) masa madya Wayang Purwa dan penemuan bentuk Wayang Palembang, dan 3) Wayang Palembang di masa kolonialisasi.

a. Awal Kedatangan Wayang Purwa di Tanah Palembang

Menurut beberapa sumber salah satunya pada candi Panataran terdapat arca dan relief-reliefnya yang menceritakan kisah Ramayana namun dengan corak yang berbeda dengan candi Prambanan (Sri Mulyono, 1982:71). Hal ini mengindikasikan bahwa pada masa Majapahit kisah Ramayana menjadi sesuatu yang sangat dijunjung tinggi oleh masyarakatnya. Mahabarata dan Ramayana terus bertahan dan berhasil masuk dengan mapan ke ranah kerajaan taklukannya salah satunya Palembang. Cerita Ramayana dan Mahabarata dan beberapa cerita lainnya merupakan bagian dari cerita-cerita klasik Wayang Palembang yang terus dipertahankan. Hadirnya cerita Ra- mayana dan Mahabarata memberikan peng aruh besar kepada Wayang Palembang yang mengadopsi lakon-lakon Wayang Purwa dan mengadaptasi cerita tersebut.

b. Masa Madya Wayang Purwa dan Penemuan Bentuk Wayang Palembang

1. Pengaruh Kerajaan Demak

Pada tahun 1525 Raden Ketib sebagai pribumi Palembang diangkat menjadi wakil kerajaan Demak di Palembang. Dari sinilah dunia pewayangan mulai menguat di kalangan pribumi Palembang. Masa kerajaan Demak telah mengubah bentuk wayang yang bernuansa Hindu dengan menimbang syariat-syariat Islam. Adapun wayang yang bernuansa hindu di teruskan ke Pulau Bali

Pengaruh Demak dapat disaksikan secara langsung, beberapa di antaranya adalah bentuk Wayang Palembang yang pipih, wajah tokoh wayang yang dibuat miring, menggunakan tabir yang lebar, memiliki tokoh-tokoh ricikan, memiliki kotak wayang namun dirubah dan dipadukan menjadi instrumen kecrek, wayang berada di sisi kiri dan kanan dalang, dan laras ansambel kongkongan yang bercampur antara slendro dan pelog.

2. Pengaruh Kerajaan Cirebon

Berdasarkan perintah kerajaan Demak Kemas Anom Jamaludin putra dari pangeran Wirakusuma cucu dari raja Cirebon Walasungsang bersama istrinya Nyimas Ilir datang ke Palembang dan

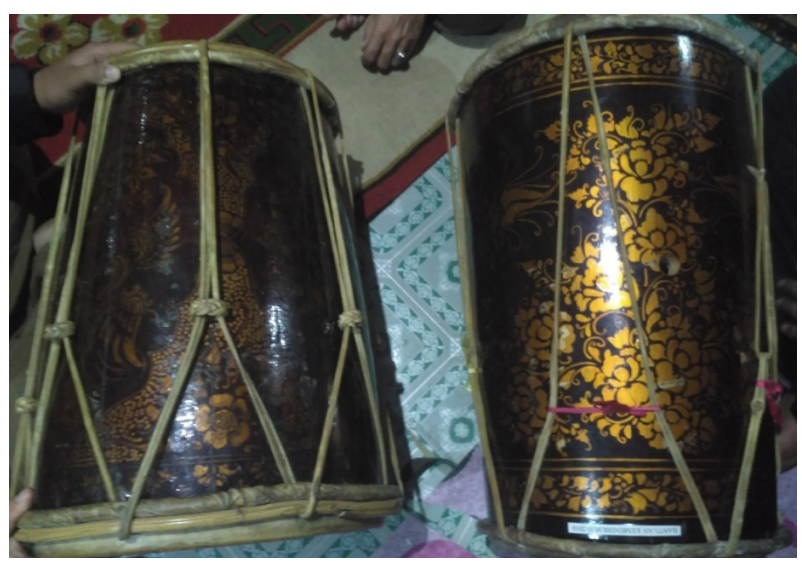

Gambar 1. Gendang Wayang Palembang, kiri lama dan kanan reproduksi. (Foto: Aminatul Fadila, Tangga Buntung, 26 Agustus 2018) 
naik tahta menggantikan Raden Ketib dengan gelar Ki Gede ing Suro. Berdasarkan fenomena ini terjadi kerjasama antara masyarakat Palembang dan pihak Kemas Anom Jamaludin, sehingga berdiri kerajaan baru yang bernama kerajaan Palembang Darussalam (Margaret J. Kartomi, 2017: 137)

Kesultanan Palembang Darussalam lahir pada tahun $1659 \mathrm{M}$ dan dipimpin oleh raja pertamanya,yaituSriSusuhunan Abdurrahman (Poesponegoro, 1985: 78). Berdirinya kerajaan Palembang Darussalam, distrik kerajaan Demak yang dipimpin oleh Kemas Anom yang berdarah Cirebon tidak hanya memberikan seperangkat alat wayang beserta alat musik pengiringnya sebagai tanda persaudaraan namun juga mengutus para seniman Jawa untuk menjadi dalang dan pengrawit pertama di Kesultanan Palembang Darussalam. Para seniman Jawa ini pada akhirnya diminta untuk mengajar 10 dalang pertama beserta penabuh masyarakat Palembang, yang menjadi pelopor seniman Wayang Palembang.

c. Wayang Palembang di Masa Kolonialisasi

Setelah sekian lama berdiri akhirnya kerajaan Palembang Darussalam pada tahun 1823 M diserang oleh kolonial Belanda hingga hancur dan hanya menyisakan kelompok-kelompok pemberontak yang berasal dari trah kerajaan.

Di balik runtuhnya kerajaan Palembang Darussalam membawa hikmah tersendiri bagi Wayang Palembang. Hikmah tersebut adalah lahirnya bentuk baru yang khas dari Wayang Palembang itu sendiri. Hal ini disebabkan oleh revitalisasi para seniman Wayang Palembang yang berusaha menduplikasi kembali seperangkat Wayang Palembang dan alat musiknya yang sudah hancur dengan daya kreativitas dan interpretasi mereka masing-masing. Alhasil terjadilah adaptasi luar biasa yang dilakukan oleh para praktisi Wayang Palembang pasca runtuhnya kerajaan Palembang Darussalam.
Setelah perekrutan selesai dan Kesultanan Palembang diruntuhkan Belanda terjadi adaptasi yang dilakukan oleh kelompok seniman Wayang Palembang terhadap kesenian ini. Di antaranya adalah menciptakan tuning atau stem nada atau laras sendiri yang berbeda dari Jawa, menciptakan nama tokoh yang diangkat dari istilah lokal, mengadopsi cerita-cerita rakyat Melayu dan dimainkan dalam format Wayang Palembang, lahir musik-musik baru denagan rantak Melayu yang dominan sebagai pengiring wayang, mengubah bentuk tatahan, mendekonstruksi bentuk instrumen bonang barung pada gamelan Jawa menjadi Kongkongan.

Pertunjukan Wayang Palembang yang dipentaskan oleh Sanggar Sri Palembang selalu menggunakan urutan pertunjukan seperti yang telah dijabarkan di atas. Adapun urutan ini menurut Kiagus Wirawan telah dilakukan secara turun-temurun. Perlu sekiranya dimengerti tentang unsur-unsur yang terkandung di dalam sebuah pertunjukan Wayang Palembang. Adapun uraiannya sebagai berikut:

a. Caturan

Istilah caturan dalam Wayang Palembang terdiri dari tiga, yaitu ginem, janturan dan pocapan. Pemaknaan caturan dalam Wayang Palembang sejatinya memilik makna tersendiri yang terurai sebagai berikut. Ginem adalah sebuah penggambaran dalang tentang dialog beberapa tokoh Wayang Palembang

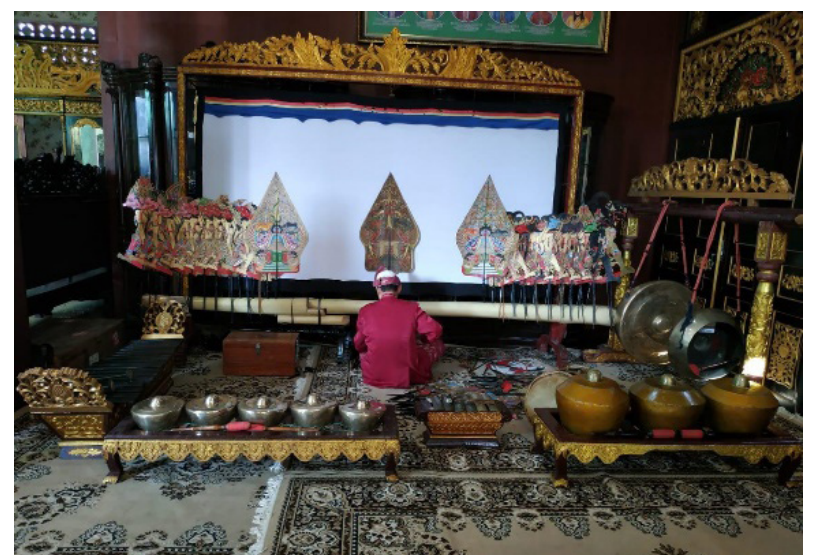

Gambar 2. Bentuk pertunjukan Wayang Palembang dalam Lakon Bambang Dharmojati.

(Dokumentasi: Dila) 
dalam sebuah adegan. Penggambaran ini akan disesuaikan dengan tokoh masingmasing melalui aksen dan dialek dalang. Janturan dalam caturan Wayang Palembang merupakan sebuah penggambaran dalang yang lebih khusus kepada suasana suatu adegan yang sedang berlangsung. Dalam pertunjukan Wayang Palembang oleh sanggar Sri Palembang janturan diiringi dengan Gending Sriwijaya berbeda dengan wayang kulit Jawa yang diiringi dengan gendhing kajantur (Mudjanatattistomo, 1977: 14). Pocapan adalah narasi yang diucapkan oleh dalang dan menceritakan peristiwa yang telah, sedang serta nantinya akan terjadi. Pengucapan narasi ini dapat berupa tampilan di tabir yang kosong maupun tidak kosong. Pocapan pada Wayang Palembang mengambil 2 unsur sekaligus yakni kandha dan carita.

b. Sabet

Secara konseptual sabet dalam istilah Wayang Palembang memiliki makna menggerakkan tubuh Wayang Palembang. Gerakan-gerakan dalam sabet tidak hanya terdiri dari satu jenis gerakan, melainkan berbagai macam gerakan. Sabet dalam Wayang Palembang terdiri dari lima bagian yaitu:

1. Cepengan (sikap) atau attitude dalam memegang Wayang Palembang.

2. Solah atau sebuah kontekstual gerak di atas tabir. Istilah ini merupakan istilah yang mengkonteks seluruh gerak Wayang Palembang di atas tabir.

3. Bedholan atau tindakan ketika seorang dalang mencabut Wayang Palembang dari posisi tanjeban.
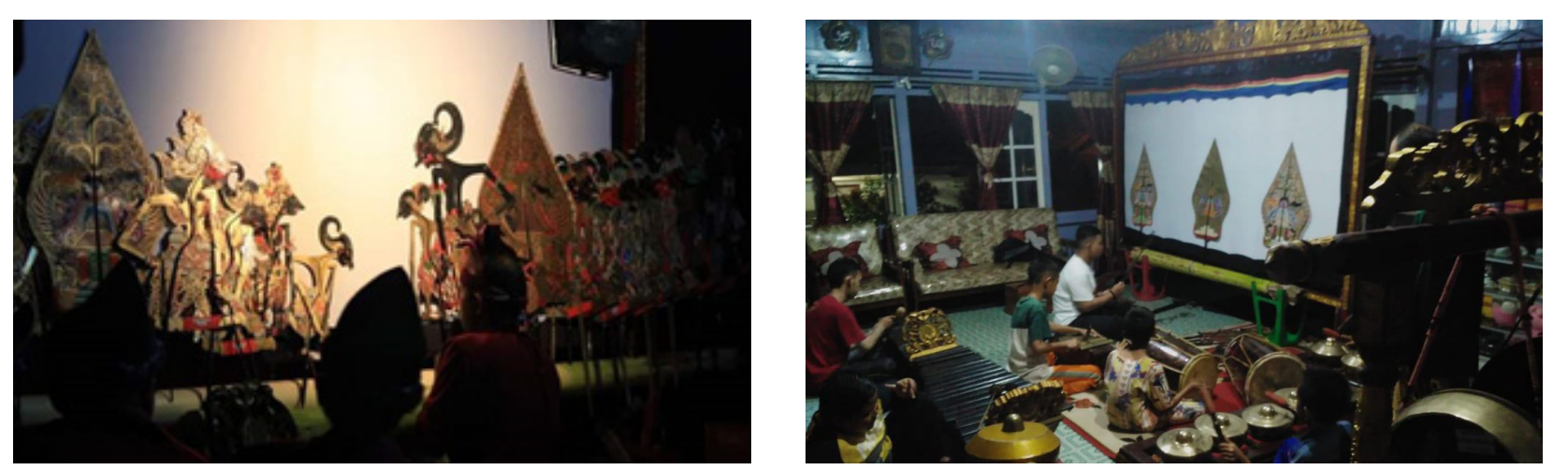

Gambar 3. Bentuk pertunjukan Wayang Palembang dalam Lakon Bambang Dharmojati. (Dokumentasi: Dila)

4. Tanjeban atau istilah ketika dalang menancapkan Wayang Palembang di batang pisang selama proses pementasan.

5. Entas-entasan atau sebuah gerakan ketika Wayang Palembang masuk ataupun pergi meninggalkan tabir. Gerakan ini meliputi seluruh aspek gerak keluar masuk tabir.

c. Lakon

Lakon dalam Wayang Palembang berakar dari lakon Wayang Jawa. Namun yang menjadi pembeda adalah lakon dalam Wayang Palembang sudah banyak mengalami adaptasi seperti adaptasi bahasa Jawa menjadi bahasa Palembang, adaptasi bentuk penyajian dan cerita lakon berdasarkan cerita rakyat dan fenomena sosial masyarakat Palembang. Oleh sebab terjadinya berbagai adaptasi inilah lakon dalam Wayang Palembang disebut sebagai lakon carangan yang memiliki arti harfiah lakon yang berubah tetapi masih memiliki unsur-unsur pokok.

d. Waktu pementasan

Pada zaman dahulu Wayang Palembang dipentaskan mulai ba'da isya hingga adzan shubuh, sebaliknya pada zaman Kiagus Wirawan Wayang Palembang hanya dipentaskan kurang lebih 1 sampai 3 jam.

e. Tempat pertunjukan

Tempat pertunjukan dalam hal ini bukanlah hal yang semata-mata memiliki arti sebuah teritori wilayah di mana pertunjukan Wayang Palembang dilakukan. Akan tetapi tempat yang dimaksud di sini adalah ruang pertunjukan baik berupa ruang fisik maupun digital. Pada masa kerajaan Wayang Palembang dipentaskan 
dalam ruang khusus di dalam wilayah kerajaan. Selanjutnya pada masa pasca kerajaan Wayang Palembang dipentaskan di wilayah lapang baik berupa lapangan, halaman rumah dan lain sebagainya. Memasuki masa sanggar Sri Palembang, pada tahun kepemimpinan dalang Kiagus Rusdi Wayang Palembang dipertunjukan di stasiun televisi lokal dan tidak hanya dipentaskan dalam wilayah lapang melainkan juga sosial media terkini seperti facebook dan instagram.

f. Wayang

Wayang dalam pertunjukan sanggar Sri Palembang diatur berdasarkan watak dan karakter wayang itu sendiri. Pengaturan ini dalam bahasa Wayang Palembang disebut sebagai simpingan yang terbagi menjadi simpingan kanan (tokoh wayang protagonis), simpingan kiri (tokoh wayang antagonis), wayang dhudahan (wayang yang berqaada di dekat kotak wayang), wayang panggung (wayang yang sedang berada dalam adegan panggung) dan wayang ricikan (wayang tokoh pembantu).

g. Gunungan Wayang Palembang

Meskipun gunungan memiliki bentuk serupa dengan wayang, yaitu 2 dimensi, gunungan tetap dikatagorikan terpisah dari wayang itu sendiri. Hal ini karena tugas dari gunungan yang berbeda dari tugas wayang dalam jalan pertunjukan Wayang Palembang.

h. Kongkongan

Kongkongan adalah seperangkat ansambel musik yang mengiringi jalannya pertunjukan Wayang Palembang yang terdiri dari 9 orang pemain dan terdiri dari 11 instrumen musik. Di antara kedelapan pemain musik kongkongan yang dalam bahasa Palembang disebut sebagai penaboh, terdapat salah seorang yang bertugas memainkan 2 instrumen sekaligus yaitu pemain gong, sehingga 11 instrumen tersebut dapat dimainkan oleh 9 orang penaboh. Jika mengklasifikasi instrumen kongkongan dalam Wayang Palembang menurut teori Erich Moritz von Hornbostel dan Curt Sach (Hornbostel and
Sach, 1914: 553) yang membagi klasifikasi instrumen musik menjadi 4 golongan, yaitu idiophone, membranophone, aerophone dan chordophone maka akan diperoleh 2 pengklasifikasian dalam ansambel kongkongan yaitu idiophone yang terdiri dari saron kecik, saron besak, kongkongan, gong, kempul, gambang, kecrek dan kenong serta membranophone terdiri dari sepasang gendang wayang.

i. Pendukung Pertunjukan Wayang Palembang

Pendukung pertunjukan dalam hal ini ditujukan untuk benda-benda yang menjadi kebutuhan dalam pertunjukan sanggar Sri Palembang baik yang bersifat primer, sekunder ataupun tersier. Adapun uraian berdasarkan pembagian kebutuhan dalam pendukung pertunjukan sanggar Sri Palembang adalah sebagai berikut:

a. Pendukung primer atau pendukung utama dalam pertunjukan Wayang Palembang versi sanggar Sri Palembang adalah pendukung yang memiliki posisi sangat penting dalam pertunjukan Wayang Palembang. Dikatakan demikian karena tanpa adanya benda-benda ini maka pertunjukan Wayang Palembang tidak dapat dipertunjukan secara sempurna. Adapun beberapa item-item pendukung tersebut adalah tabir, cagak tabir, batang pisang dan sumber cahaya (zaman dahulu berupa lampu minyak berukuran kecil yang digantung dan kini berganti lampu elektrik yang digantung).

b. Pendukung sekunder atau yang bersifat cukup penting dalam pertunjukan Wayang Palembang adalah pakaian adat, kotak wayang dan microphone. Ketiga hal ini menjadi cukup penting karena mampu menunjang performa pertunjukan. Contoh pakaian adat yang terdiri dari songket, tanjak dan baju tradisional mampu menciptakan daya tarik tersendiri dan membangkitkan aura dari para praktisi Wayang Palembang di atas panggung. Selanjutnya dapat juga dilihat contoh melalui kotak Wayang Palembang dan microphone yang 
sangat membantu pertunjukan Wayang Palembang.

c. Pendukung Tersier dalam pertunjukan Wayang Palembang adalah makanan berat, jajanan dan minuman. Ada dan tidak nya makanan tidak menjadi faktor yang mengurangi kemaksimalan pertunjukan sanggar Sri Palembang, hal ini didukung juga oleh durasi pertunjukan sanggar Sri Palembang yang berkisar 1 sampai 3 jam dan tidak melakukan pertunjukan semalam suntuk.

\section{Wayang Palembang dan Pemerintah Palembang}

Jika sebuah karya seni masih menjadi suatu hal yang populer hingga saat ini, hal tersebut dikarenakan seniman penciptanya mampu berubah mengikuti arus permintaan ruang pertunjukan. Perubahan kesenian di Palembang yang terjadi selalu mengikuti trend dan fashion masyarakat Palembang. Pemerintah khususnya Dinas Pariwisata dan Dinas Kebudayaan diharapkan mampu mengambil garis tengah untuk menetralisir gejolak kontaminasi dalam seni. Akan tetapi kedua lembaga tersebut justru ikut terbawa arus. Tidak sedikit program seni kedinasan dalam ranah pertunjukan dan pemberdayaan yang terjadi sepanjang tahun. Kendati demikian kelompok sanggar Sri Palembang mengaku kerjasama yang dilakukan pemerintah setempat terakhir dilakukan pada tahun 2010. Kerjasama antara sanggar Sri Palembang dan Pemerintah dianggap menguntungkan sebelah pihak sehingga kelompok Sri Palembang mengakhiri kerjasama dengan pihak pemerintah selama 8 tahun. Kiagus Wirawan mengaku setelah merasa tereksploitasi dia memiliki trauma yang cukup kuat terhadap kedinasan setempat. Putusnya kerjasama antara kedua belah pihak bukan semata kesalahan dari pemerintah murni. Konflik ini tercipta atas dialektika antara masyarakat, seniman dan pemerintah yang berbeda pandangan.

Masyarakat Palembang yang sudah menjadi masyarakat instan tidak lagi menaruh perhatian lebih pada Wayang Palembang, sehingga pemerintah merasa pertunjukan Wayang Palembang tidak memberikan feedback bagi audiens. Dan dalam programprogram seni pertunjukan yang akan dilakukan mereka tidak lagi menghadirkan Wayang Palembang. Hilangnya pertunjukan Wayang Palembang dari program rutin pemerintah selama beberapa periode pemerintah daerah membuat masyarakat semakin tidak mengenal Wayang Palembang. Pola yang berlangsung cukup lama ini menjadikan istilah Wayang Palembang kini semakin asing di telinga masyarakat Palembang.

\section{Wayang Palembang dan Konflik Sosial}

Seni umumnya dan seni Pertunjukan khususnya merupakan arena pergulatan batin, konflik-konflik sosial dan persoalan status di dalam diri manusia yang tarik-menarik. Jika seni sudah dimasuki urusan ekonomi, maka orang-orang akan melihat dirinya di telah diberi label harga. Apa yang menjadi kesukaan seseorang belum tentu disukai oleh orang lainnya. Orang-orang jarang sepakat tentang interpretasi terutama dalam wilayah seni pertunjukan, tidak terkecuali Wayang Palembang. Bukan hal yang baru ketika Wayang Palembang seolah-olah dilarang tampil di ruang publik secara halus oleh pihak tertentu. Sering terjadi pula dukungan ekonomi yang kurang bagi kelompok Wayang Palembang, sedangkan kelompok genre seni lainnya mendapatkan limpahan dana besar untuk produksi karyanya. Banyak masyarakat Palembang yang menganggap bahwa tinggi rendahnya kualitas seni berpengaruh terhadap ada atau tidaknya dukungan pihak tertentu. Padahal pada kenyataanya tidak ada hubungan di antara kualitas seni dan para pendukung. Menurut Rozenberg (1994) hal ini disebut sebagai waktu yang menyebabkan perubahan nilai.

Jadi kualitas ataupun nilai Wayang Palembang dalam masyarakat merupakan suatu yang relatif. Bagaimanapun dalam konteks masyarakat yang luas bukanlah kualitas yang menjadi hal utama, melainkan 
kriterialah yang menentukan mengapa Wayang Palembang redup dan seni yang lain justru lebih menonjol. Tidak mudah untuk menentukan kriteria dalam Wayang Palembang, karena kriteria dapat berbedabeda dari waktu ke waktu dan masyarakat ke masyarakat. Pada dasarnya seperti yang telah disebutkan dalam pembahasan sebelumnya bahwa kekuasaan mampu menentukan status tinggi atau rendahnya Wayang Palembang di mata masyarakat. Seperti sebuah contoh yang dikemukan oleh Apinan Poshyananda (1992) bahwa:

...kekuasaan mampu untuk menggeser derajat nilai komersil dan derajat nilai estetika yang bekorespondensi secara langsung. Dengan memiliki pandangan kelompok mereka sendiri atas seni modern Thailand, lembaga-lembaga ekonomi dan finansial ini memiliki kekuasaan untuk menyetujui atau mengesahkan seni yang mereka anggap bagus dan mendeskriminasikan seni yang mereka anggap sebagai seni yang buruk. Dengan cara ini patron-patron perusahaan dan komite-komite pilihan mereka dapat mendikte estetika dan finansial dunia seni Thailand.

Pernyataan di atas membawa permasalahan hubungan kompleks antara seni, komoditas dan cita rasa. Saat ini dapat disaksikan bahwa keberhasilan bergelut dalam seni yang dianggap sebagai hal modern telah menjadi sebuah simbol status. Bagi orang yang hidup di kota Palembang bergelut dalam seni modern akan mendemonstrasikan prinsipprinsip mereka mengenai nilai dan kausalitas di dalam sebuah masyarakat yang mati-matian berusaha menyamai kapitalisme dunia barat.

Kelompok sanggar Sri Palembang sebagai penggerak Wayang Palembang meskipun terdeskriminasi tidak pernah mundur dalam menghadapi friksi yang datang dari berbagai arah. Meskipun telah memasuki arena persaingan ketat, sanggar Sri Palembang tetap mampu membuktikan kekuatannya. Semakin banyak serangan yang datang, maka semakin banyak pula mereka belajar cara bertahan.

\section{Perlawanan dan Cara Bertahan Sanggar Sri Palembang}

Akar kata resistensi mengacu dalam kamus Oxford (1995), resistance (perlawanan) sebagai aksi yang dilakukan untuk bertahan, menentang dan perlawanan. Makna resistensi berdasarkan aksinya memberikan makna sebagai aktifitas kolektif. Menurut James Scott (1985: 83) terdapat dua model perlawanan yaitu "open and hidden forms of resistance". Sanggar Sri Palembang jika meninjau pernyataan Scott telah melakukan kedua gerakan tersebut. Dalam gerakan open forms of resistance atau perlawanan terbuka, sanggar Sri Palembang secara tegas menolak ruang pertunjukan kapital yang menerapkan syarat implan dalam format pertunjukan Wayang Palembang dan menciptakan ruang pertunjukan sendiri. Syarat implan yang dimaksud di sini ialah syarat agar kelompok sanggar Sri Palembang mau untuk merubah dan mencampur aduk pertunjukan Wayang Palembang dengan unsur-unsur modern agar mampu menghadirkan nilai jual (materil) bagi penyelenggara. Selanjutnya gerakan hidden form of resistance atau gerakan tertutup juga turut serta dilakukan dalang Kiagus Wirawan dengan menebarkan pemahaman wayang klasik sebagai bentuk estetika yang harus dijunjung tinggi melalui penjaringan keanggotaan sanggar yang tidak memandang umur.

Teknik penjaringan seperti di atas terbilang cukup strategis. Kiagus Wirawan menerapkan pembelajaran wayang kepada anak-anak yang berada di lingkungan sekitar desa. Pembelajaran ini dilakukan secara gratis, dimulai dari anak yang duduk dibangku sekolah dasar hingga sekolah menengah pertama. Tidak hanya anak-anak, para remaja dan orang dewasa banyak yang telah menjadi anggota dan alumni sanggar Sri Palembang.

Kiagus Wirawan adalah aktor dalam gerakan resisten sanggar Sri Palembang yang melibatkan anggota-anggotanya sebagai partisipan. Kiagus Wirawan dapat juga dikatakan sebagai self (kedirian) yang mengcounter agent dalam sistem dominasi. Hingga 
saat ini idealisme Kiagus Wirawan dalam menyikapi alienasi yang dilakukan masyarakat Palembang (pemerintah,masyarakat umum dan lain-lain) tidak pernah dan belum juga padam. Kiagus Wirawan beserta kelompoknya hingga saat ini terus berupaya mengembangkan gerakan-gerakan sosial melalui media sanggar Sri Palembang. Kiagus Wirawan seringkali menggelar pertunjukan Wayang Palembang di studio sanggar Sri Palembang secara independen dengan biaya pribadi. Meskipun minim penonton Kiagus Wirawan tetap menjalankan program pertunjukan tersebut. Alih-alih sembari melakukan pertunjukan, kegiatan ini juga diperuntukkan agar keterampilan para praktisi Wayang Palembang tetap terasah. Cara demikian akan terus dilakukan untuk menyikapi ruang-ruang pertunjukan yang dirasa sudah tidak lagi bersahabat.

\section{Penutup}

Pertunjukan Wayang Palembang dalam lakon Bambang Dharmojati memiliki alur maju. Tema yang digunakan ber-genre klasik dengan suasana tragedi. Setiap pementasan dalam waktu yang berbeda akan selalu menghasilkan dialog yang berbeda pula. Akan tetapi yang menjadi substansinya adalah jalan cerita dan plot yang secara garis besar tidak berubah.

Turunnya minat penonton disebabkan oleh tidak sinkronnya antara kondisi masyarakat Palembang yang lebih tertarik terhadap seni atraktif dan kepedulian pemerintah terhadap Wayang Palembang yang masih dipertahankan dalam bentuk kuna. Masyarakat sebagai apresiator dan pemerintah sebagai fasilitator selalu berjalan beriringan, dan bertolak dari eksistensi Wayang Palembang sebagai sebuah seni yang mebutuhkan apresiasi serta fasilitas. Kendati demikian Kiagus Wirawan memiliki cara sendiri menangani hal ini. Selama Sanggar Sri Palembang masih ada, maka secara otomatis panggung Wayang Palembang tetap akan dihadirkan di studio Tangga Buntung sebagai gerakan melestari- kan dan memperankan adat budaya setempat. Mereka tidak peduli ada atau tidaknya penonton, yang mereka tanamkan kepaga generasi penerusnya adalah setiap satu minggu sekali Wayang Palembang harus tetap dipentaskan, dengan segenap tantangannya.

\section{Kepustakaan}

Apinan, Poshyananda. 1992. Modern Art in Thailand, Singapura. Oxford University: Oxford University Press.

Hornby, A.S. 1995. Oxford Advanced Learner's Dictionary, Oxfor University Press, hal 998.

Kartomi, Margaret J. 2017. Musical Journey in Sumatera, Champaign: University of Illinois Press.

Kuardhani, Hirwan. 2014. "Potehi : Teater Boneka Tionghoa Peranakan di Jawa (Kajian Bentuk, Struktur dan Fungsi Pertunjukan)", Disertasi Program Doktoral Pengkajian Seni Pertunjukan dan Seni Rupa Universitas Gajah Mada.

Labberton, Hinloopen. 1914. The Wayang Sadhow Play as Give in Java. Cambridge: The Belknap Press on Harverd University. Mulyono, Sri. 1982. Wayang "Asal-usul, Filsafat dan Masa Depannya", Jakarta: Gunung Agung.

Poesponegoro, 1985. Sejarah Nasional Indonesia: Jaman Pertumbuhan dan Perkembangan Kerajaan-kerajaan Islam di Indonesia. Jakarta: Balai Pustaka.

Rozenberg, Rob. 1994. Zimbabwe. Huis van steen, Amsterdam: Menno van de Koppel.

Sach, Hornbostel and. 1914. Zeitschrift Vol 46, Canada:University of Toronto.

Scott, James C. 1985. Weapons of the Weak: Everyday Forms of Resistance, New Haven and London: Yale University Press. Scott, James C. 1993.

Sunyoto, Agus. Suluk Abdul Jalil, Perjalanan Rohani Syaikh Siti Jenar Volumer 5. Bantul: Lukis Pelangi Aksara.

Yudiaryani. 2002. Panggung Teater Dunia, Perkembangan dan Perubahan Konvensi, Yogyakarta: Pustaka Gondho Suli. 


\section{Internet}

http://www.abs.gov.au/ausstats/abs@.nsf/ $\mathrm{mf} / 1217.0 .55 .001$, Glossary of Statistical Geography Terminology, diakses pada tanggal 4 Desember 2018 pukul 18.30 WIB.

\section{Informan}

Kiagus Wirawan, 35 tahun, Kelurahan 36 Ilir, Kecamatan Ilir Barat 2, Desa Tangga Buntung, Kota Madya Palembang.

Kiyai Akbar, 40 tahun, Pandan Agung, RT 05. RW 02 Sumatera Selatan. 